\title{
Psychosocial correlates of physical activity levels in individuals at risk of developing diabetes mellitus: A feasibility study.
}

Caden Shields BSC, BPhty

Physiotherapist, Physio Performance Ltd, Dunedin, Otago

David Baxter BSC(Hons), DPhil, MBA

Director of Ageing Well and the Centre for Health, Activity and Rehabilitation Research, School of Physiotherapy, University of Otago, Dunedin, Otago, New Zealand

Ramakrishnan Mani DAc, BPhty, MPhty, PGCert, PhD

Lecturer, Centre for Health, Activity and Rehabilitation Research, School of Physiotherapy, University of Otago, Dunedin, Otago, New Zealand

\section{ABSTRACT}

Recognition of psychosocial factors associated with physical activity (PA) levels will facilitate development of targeted behavioural interventions to promote PA. The aims of this feasibility study were to screen individuals at risk of diabetes mellitus (DM), to quantify their physical activity (PA) levels and to investigate the associations between PA levels, exercise self-efficacy (ESE), psychological flexibility (PF) and health-related quality of life (HRQoL). Twenty-six adults at risk of developing DM were recruited. Participants demographics, anthropometrics, ESE, PF and HRQoL, step counts using pedometers and self-reported PA levels (New Zealand physical activity questionnaire) over a 7-day period were collected. Participants' mean (SD) age, weight and BMI were 41.4 (13.2) years, $71.4(17.5) \mathrm{kgs}$, and $26.39(8.41) \mathrm{kg} / \mathrm{m}^{2}$, respectively. Based on daily step counts, $32 \%$ of participants were classified as "low active". Mean (SD) scores of ESE, PF, HRQOL: physical (PCS) and mental component scores (MCS) were $3.4(0.9)$ and, 47.8 (6), 51.4 and 49.2, respectively. ESE and MCS scores were positively associated with vigorous PA minutes/week $\left(R^{2}=0.17 ; p=0.04\right)$ and moderate PA minutes/week $\left(R^{2}=0.20 ; p=0.03\right)$, respectively. This feasibility study highlights the potential association of positive psychosocial attributes in determining PA levels in a cohort of individuals at risk of developing DM.

Shields C, Baxter D, Mani R (2016) Psychosocial correlates of physical activity levels in individuals at risk of developing

Key words: Prediabetes; Physical Activity; Self-efficacy; Psychological flexibility; Quality of life

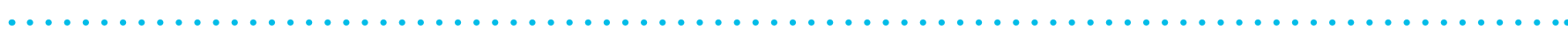

\section{INTRODUCTION}

The New Zealand Adult Nutrition Survey (2013) reported a $7 \%$ prevalence of diabetes mellitus (DM) in the New Zealand population, with a higher prevalence of pre-diabetes (26\%) among Māori and Pacific people (Coppell et al 2013). Prediabetes refers to a state in which people are at high risk of developing diabetes (Eikenberg and Davy 2013). The high prevalence of pre-diabetes in those who identify as Māori and Pacific is concerning, as it represents a lead measure for the incidence of diabetes (Tabak et al 2012).

Modifiable risk factors for the development of DM include diet and physical activity (PA) (Orozco et al 2008). Several randomised controlled trials conclude that increasing PA with or without inclusion of a healthier diet results in reduction of DM development rates (Laaksonen et al 2005, Orchard et al 2005). Furthermore, public health recommendations on PA thresholds have been proposed to promote health and reduce the risk of developing chronic diseases such as DM (Haskell et al 2007). Despite these PA health recommendations and with a supporting body of research, many adults choose not to exercise, even when they know PA is key to maintaining and improving their health (Bauman et al 2012). A range of personal, social and environmental factors have been shown to influence an individual's decision to initiate or maintain levels of PA (Battistelli et al 2012, Bauman et al 2012).

Health behaviours can be explained using a psychosocial framework such as 'social cognitive theory' (Bandura 2004). This theory explains that a health behaviour is based on complex interactions between three key variables: behaviour, the person, and the environment (Bandura 2004). A key construct based on social cognitive theory is self-efficacy, which refers to "beliefs in one's capabilities to organise and execute the courses of action required to produce given attainments" (Bandura 1997). Higher levels of self-efficacy have been consistently identified as a positive psychological mechanism behind exercise adherence among clinical and non-clinical populations (Allen 2004, Izawa et al 2006). Furthermore, increased self-efficacy has been recognised as a strong mediator of lifestyle change interventions which result in successful outcomes (Papandonatos et al 2012, Rhodes and Pfaeffli 2010).

Recently, psychological flexibility (PF) and experiential avoidance have been recognised as important factors in understanding purposeful behaviour while dynamically representing wellbeing and life satisfaction (Kashdan and Rottenberg 2010). Psychological flexibility refers to the ability to be in the present moment with full awareness and openness to experiences based 
on one's own life values (Hayes et al 2006). Several unhealthy behaviours have been associated with poor PF. In regard to PA, PF has been considered an aversive cognitive situation that can be associated with physical inactivity (Kangasniemi et al 2014). Interventions which target improving one's PF, such as acceptance and commitment therapy, have achieved positive health behaviours including increasing PA among physically inactive adults and reducing weight in obese individuals (Kangasniemi et al 2015, Lillis et al 2009).

Diabetes is one of a range of chronic health conditions that have a significant impact on Health Related Quality of Life (HRQoL) (Brown et al 2004). Cross-sectional and longitudinal studies have identified positive associations between PA domains and HRQoL in various clinical and non-clinical population groups (adolescents, middle aged and older adults) (Bize et al 2007, Klavestrand and Vingård 2009). Research has also identified similar associations in individuals with pre-diabetes (Taylor et al 2010). However, such associations are primarily based on selfreport measures of PA (Taylor et al 2010). In addition, decreasing HRQoL has been reported in individuals with newly diagnosed and chronic type-2 DM, but not in those with pre-diabetes (Marcuello et al 2012, Seppälä et al 2013). Since physical and mental health characteristics vary significantly between those with and without DM and those with pre-diabetes (Tapp et al 2006), it can be argued that health-related perceptions that influence behaviour are also different. In addition, there are reports suggesting that lower levels of perceived stress, depression and anxiety are associated with higher levels of PA in individuals with impaired glucose tolerance (Delahanty et al 2006) and in those with diabetes (Sacco et al 2007, Sacco et al 2005).

The influence of psychological profiles, such as PF, HRQoL and ESE on objective PA levels has not yet been determined in individuals who are at risk of developing DM. Before investigating new variables of interest (such as PF) as a potential predictor of PA levels in a fully-powered sample, it is justified to establish cross-sectional associations in a smaller number of individuals. In addition, the feasibility of using simple screening tools (such as self-report questionnaires) to recruit participants with a risk of developing DM needs to be assessed. Therefore, the aims of this feasibility study were to: (1) identify participants at risk of developing DM, using self-reported risk screening tools; (2) gather feasibility data related to PA levels via selfreported and objective measures; and psychosocial factors including exercise $\mathrm{SE}, \mathrm{PF}$, and $\mathrm{HRQOL}$, and (3) determine the cross-sectional associations between PA levels and selective psychosocial factors such as exercise SE, PF, and HRQoL. Establishing such bivariate associations between the selected range of factors and PA levels could provide direction to choose suitable variables for conducting definitive studies on predictive associations, which will further facilitate the development of potential targets for interventions and thus reduce the impact of chronic diseases.

\section{METHOD}

Study design and ethical approval

This study was a cross-sectional investigation that was conducted between November 2013 and January 2014. Ethical approval was granted from The University of Otago Human Research Ethics Committee (Ref.no: D13/396), Dunedin, New Zealand.

\section{Participants}

A consecutive sampling strategy was used to recruit 26 adults (aged 18-60 years) with a risk of developing type-2 DM who were living in the Dunedin community. Participants were recruited from the University of Otago via email invitation and from the wider Dunedin community through flier advertisements. Interested volunteers contacted the research administrator for confirmative eligibility screening procedures. Each participant's risk of developing DM was identified using an online screening tool (Diabetes New Zealand, Auckland branch) that was administered by telephone by the clinical research administrator. Those who were at or above the "at risk" level of risk of developing DM were included in the study. Participants were excluded if they had the following conditions or situations: a current history of muscle and/or bone disorders, surgery in the last 6 months, heart or lung illnesses that restricted their current PA levels, a recommendation by a health professional not to engage in PA or any formal programme that aimed to increase their PA levels. All participants provided informed written consent to participate in the study.

\section{Outcome measures}

\section{Physical activity measures}

The New Zealand Physical Activity Questionnaire-Long Form (NZPAQ-LF) is a 7 day recall of total PA administered through an interview method. It is a validated measure of PA within the New Zealand population that includes many New Zealand cultural activities such as kapa haka (Boon et al 2010). Over a 7 day period, participants' ambulatory levels were quantified using pedometers (Yamax Digi-Walker SW-200, Japan) which possess moderate test-retest reliability and good validity (Kooiman et al 2015). Participants were instructed to record the number of steps they took each day in a step count log. Participants were instructed to turn the pedometer on in the morning as soon as they got out of bed, and to record the duration of time in which they took off the pedometer throughout the day for any particular reason, and any activity they performed that was not running or walking. The intensity levels of other activities besides running or walking were recorded based on the intensity definitions from the NZPAQ-LF.

\section{Psychosocial measures}

Stage of readiness (i.e. current participation or plans to participate in planned PA) was measured using the Exercise Stages of Change questionnaire (Astroth et al 2010, Dannecker et al 2003), a questionnaire used previously in a pre-diabetic population (Delahanty et al 2006). Exercise self-efficacy was assessed using a validated ESE scale (Marcus et al 1992). Participants rated their confidence on a scale of 1-5 with 1 being not at all confident and 5 being completely confident, with the mean score taken as the final score for self-efficacy. Level of PF was assessed using the Acceptance and Action Questionnaire (AAQ-II), a validated and reliable outcome measure (Bond et al 2011). The AAQ-II is a 10-item Likert-type questionnaire that assesses one's ability to take a non-judgemental approach to one's own internal events, so that the person can focus on the present moment and act in a way that is congruent with their 
values and goals, rather than merely reacting to their internal events (e.g., fears, urges, prejudices). Each item was rated from 1 (never true) to 7 (always true), with the total score indicative of overall PF. Participants' HRQoL was quantified using the Short Form (SF)-36v2 (Quality Metric software ${ }^{\mathrm{TM}}$ ), a 36-item tool that measures eight domains (physical function, role limitations owing to physical problems, bodily pain, general health perception, vitality, social functioning, role limitations owing to emotional problems and mental health). Two summary scores are provided: the physical health component summary score (PCS) and the mental health component summary score (MCS), with the overall score ranging from 0-100, with higher scores indicating better HRQoL (Scott et al 1999).

\section{Procedure}

Participants' age, sex, ethnicity, occupation and educational status were documented. Height, weight, waist and hip circumference were measured (Seca Alpha Model 770, Chino, CA, USA). Four-site skin fold measurements were taken using callipers (Slim Guide Creative Health Products, Plymouth Michigan) as per the American College of Sports Medicine assessment guidelines (2010). The Audit- $C$ was used as a validated screening tool for alcohol misuse (Bush et al 1998). In addition to eligibility assessment, participant's risk of developing of DM within 10 years was scored using a validated risk screening tool, the Finnish Diabetes Risk Score (FINDRISC) (Zhang et al 2014). According to the FINDRISC classification, a score of 12-14 is considered 'moderate risk' (estimated that 1 in 6 people will develop type 2 DM); 15-20 represents 'high risk' (estimated that 1 in 3 will develop disease), and > 20 is deemed to be 'very high risk' (estimated that 1 in 2 will develop disease) (Zhang et al 2014). In addition, sub-maximal exercise capacity was quantified using the six minute walk test (Crapo et al 2002).

\section{Data processing}

The amount of moderate and vigorous exercise was used to calculate metabolic equivalent (MET)-minutes per week, calculated as the MET intensity multiplied by the minutes for each class (moderate and vigorous) of activity over the seven day period (Maddison et al 2007). Activity levels were classified as "low", "moderate", or "high" based on the International Physical Activity Questionnaire (IPAQ) scoring protocol (www. ipaq.ki.se). Total minutes of moderate and vigorous activity for each participant were calculated to classify participants as either "active" or "inactive" according to their ability to meet the New Zealand Physical Activity Guidelines (NZPAG) of $\geq 150$ minutes/ week or $\geq 30 \mathrm{~min} /$ day on $\geq 5$ days per week, as previously reported (Boon et al 2010). Based on their average daily step count, participants were also categorised into activity levels of "sedentary", "low active", "somewhat active", "active", and "highly active" (Tudor-Locke and Bassett 2004).

\section{Statistical analyses}

Statistical analyses were performed using SPSS (IBM Corp. Released 2013. IBM SPSS Statistics for Windows, Version 22.0. Armonk, NY: IBM Corp). Descriptive statistics were calculated for demographic, anthropometric, PA and psychosocial variables (ESE, PF, HRQOL measures-PCS and MCS), activity levels based on IPAQ, NZPAG, and step count classifications. Alcohol intake scores of $\geq 4$ for men and $\geq 3$ for women were considered indicative of alcohol misuse based on AUDIT-C (Bush et al 1998).
Bivariate linear regression analyses $(p \leq 0.20)$ and Pearson's correlation statistics ( $p \leq 0.05)$ were performed to determine associations and correlations between PA levels (step counts, total MET minutes/week, minutes of moderate and vigorous activities), and measures of interest (ESE, PF, PCS and MCS). Due to insufficient sample size, multiple linear regression analysis was not conducted. Assumptions for regression analysis were evaluated (Field 2012). One participant failed to wear the pedometer during the study period, and this resulted in a total of 25 step count data samples for analysis.

\section{RESULTS}

Of the 26 participants identified to be at risk using the online screening tool (Diabetes New Zealand, Auckland branch), 10 (38.5\%) individuals had scores $\geq 12$ in the FINDRISC screening tool, representing a moderate-very high risk of developing DM. The participants' demographic and anthropometric data are presented in Table 1. Four female participants and one male participant were classified as 'hazardous drinkers'.

\section{Table 1: Participant characteristics}

\begin{tabular}{|c|c|c|}
\hline & $\begin{array}{c}\text { Total sample } \\
\text { ('at risk' group) } \\
n=26\end{array}$ & $\begin{array}{c}\text { 'FINDRISC group'* } \\
\text { (a subset of 'at risk' group) } \\
n=10\end{array}$ \\
\hline $\begin{array}{l}\text { Age (years) } \\
\text { Mean (SD) }\end{array}$ & $41.4(13.2)$ & 49.9 (9.9) \\
\hline \multicolumn{3}{|l|}{ Ethnicity, n (\%) } \\
\hline NZE & $11(42.3)$ & $4(40)$ \\
\hline Chinese & $4(15.4)$ & $1(10)$ \\
\hline Maori & $3(11.5)$ & $1(10)$ \\
\hline Indian & $3(11.5)$ & $1(10)$ \\
\hline Others & 5 (19.3) & $3(30)$ \\
\hline $\begin{array}{l}\text { Weight (kg) } \\
\text { Mean (SD) }\end{array}$ & $71.4(17.5)$ & $81.0(23.0)$ \\
\hline $\begin{array}{l}\text { Height (cm) } \\
\text { Mean (SD) }\end{array}$ & $164.5(6.2)$ & $162.9(3.5)$ \\
\hline $\begin{array}{l}\text { BMI (kg/m2) } \\
\text { Mean (SD) }\end{array}$ & $26.39(6.4)$ & $30.43(8.41)$ \\
\hline $\begin{array}{l}\text { Body fat (\%) } \\
\text { Mean (SD) }\end{array}$ & $\begin{array}{c}\text { M: } 17.64(3.55) \\
\text { F: } 27.40(5.18)\end{array}$ & $\begin{array}{c}\text { M: } 23.64(0) \\
F: 30.71(4.16)\end{array}$ \\
\hline $\begin{array}{l}\text { W/H ratio } \\
\text { Mean (SD) }\end{array}$ & $\begin{array}{l}\text { M: } 0.9(0.07) \\
\text { F: } 0.84(0.05)\end{array}$ & $\begin{array}{c}\text { M: } 0.99(0.01) \\
\text { F: } 0.86(0.04)\end{array}$ \\
\hline
\end{tabular}

Note: $B M I$, body mass index; $F$, female; $M$, male; $n$, number of participants; NZE, New Zealand European; Others, Canadian, Irish, Welsh; SD, standard deviation; W/H, waist to hip ratio.

*Indicates $\geq 12$ score on FINDRISC tool

Descriptive measures of PA levels, psychosocial factors and other variables are presented in Table 2. Fifty percent of participants were in the maintenance stage of exercise change. Based on the IPAQ classification, 54\% of the participants were included in the "low" activity category, however, for the NZPAG classification, $23 \%$ of participants were classified as "non-active". Based on average daily step count, $31 \%$ of participants were classified as "low active". (Table 2). 
Table 2: Descriptive indices of physical activity levels and psychosocial factors

\begin{tabular}{|c|c|c|c|}
\hline & Categories & $\begin{array}{c}\text { Total sample } \\
\text { ('at risk' group) } \\
\mathrm{n}=26\end{array}$ & $\begin{array}{c}\text { 'FINDRISC group'* } \\
\text { (a subset of 'at risk' group) } \\
n=11\end{array}$ \\
\hline Average six-minute walk distance (m) & NA & 550 & 522 \\
\hline $\begin{array}{l}\text { Physical activity levels } \\
\text { NZPAG classification } \\
\text { n (\%) }\end{array}$ & $\begin{array}{l}\text { Active } \\
\text { Non-Active }\end{array}$ & $\begin{array}{l}20(76.9) \\
6(23.1)\end{array}$ & $\begin{array}{l}8(80) \\
2(20)\end{array}$ \\
\hline $\begin{array}{l}\text { IPAQ classification } \\
\mathrm{n}(\%)\end{array}$ & $\begin{array}{l}\text { Low } \\
\text { Moderate } \\
\text { High }\end{array}$ & $\begin{array}{l}14(53.8) \\
9(34.6) \\
3(11.5)\end{array}$ & $\begin{array}{l}7(70) \\
2(20) \\
1(10)\end{array}$ \\
\hline $\begin{array}{l}\text { Average 7-day step count } \\
\mathrm{n}(\%)\end{array}$ & $\begin{array}{c}\text { Sedentary } \\
\text { Low active } \\
\text { Somewhat Active } \\
\text { Active } \\
\text { Highly Active }\end{array}$ & $\begin{array}{l}1(3.8) \\
8(30.8) \\
7(26.9) \\
3(11.5) \\
6(23.1)\end{array}$ & $\begin{array}{c}0 \\
4(40) \\
4(40) \\
1(10) \\
1(10)\end{array}$ \\
\hline $\begin{array}{l}\text { Stages of change } \\
n(\%)\end{array}$ & $\begin{array}{c}\text { Maintenance } \\
\text { Action } \\
\text { Preparation } \\
\text { Contemplation } \\
\text { Pre-contemplation }\end{array}$ & $\begin{array}{c}13(50) \\
2(7.7) \\
5(19.2) \\
5(19.2) \\
1(3.8)\end{array}$ & $\begin{array}{l}5(50) \\
0(0) \\
2(20) \\
3(30) \\
0(0)\end{array}$ \\
\hline ESE, mean (SD) & NA & $3.4(0.9)$ & $3.7(0.9)$ \\
\hline AAQ-II, mean (SD) & NA & $48(6)$ & $47(5)$ \\
\hline HRQoL, mean (SD) & $\begin{array}{l}\text { PCS } \\
\text { MCS }\end{array}$ & $\begin{array}{c}51(12) \\
49(9)\end{array}$ & $\begin{array}{c}51(6) \\
49(10)\end{array}$ \\
\hline
\end{tabular}

Notes: AAQ-II, Acceptance and Action Questionnaire II, a measure of psychological flexibility; ESE, exercise self-efficacy; HRQoL, Health Related Quality of Life (SF-36V2); IPAQ, International Physical Activity Questionnaire; MCS, mental component score, NA, not applicable; NZPAG, New Zealand Physical Activity Guidelines; PCS, physical component score.

* Indicates $\geq 12$ score on FINDRISC tool.

The mean scores for ESE, PF (AAQ-II), PCS, and MCS were 3.4, 48, 51 and 49, respectively (Table 2). ESE scores were independently associated only with vigorous minutes $\left(R^{2}=0.17\right.$; $p=0.04)$ and MET minutes/week $\left(R^{2}=0.08 ; p=0.16\right)$, but not with moderate minutes and step counts ( $p>0.20$ ) (Table 3). MCS demonstrated a significant moderate positive correlation $(r=0.41 ; p=0.04)$ with total MET minutes/week and explained a $17 \%$ of total variance $\left(R^{2}=0.17 ; p=0.04\right)$ of total MET minutes/ week. Also, MCS demonstrated a significant moderate positive correlation ( $r=0.45 ; p=0.03$ ) with vigorous minutes/week and explained $20 \%$ of total variance $\left(R^{2}=0.20 ; p=0.03\right)$ of vigorous minutes/week. However, PCS scores were not associated with PA measures (MET minutes/week, total moderate and vigorous minutes), whereas PCS scores demonstrated a small magnitude of association with step counts $\left(R^{2}=0.10 ; p=0.13\right)$. None of the PA measures (subjective or objective) were associated with PF (AAQ-II scores). 
Table 3: Relationships between physical activity levels and psychosocial factors

\begin{tabular}{|c|c|c|c|c|c|c|c|c|}
\hline \multirow[t]{3}{*}{ Variables } & \multicolumn{2}{|c|}{$\begin{array}{l}\text { Average 7-day } \\
\text { step counts }\end{array}$} & \multicolumn{2}{|c|}{ MET (min/week) } & \multicolumn{2}{|c|}{ TVIG (min) } & \multicolumn{2}{|c|}{ TMOD (min) } \\
\hline & $\begin{array}{l}\text { Bivariate } \\
\text { regression }\end{array}$ & Correlation & $\begin{array}{l}\text { Bivariate } \\
\text { regression }\end{array}$ & Correlation & $\begin{array}{l}\text { Bivariate } \\
\text { regression }\end{array}$ & Correlation & $\begin{array}{l}\text { Bivariate } \\
\text { regression }\end{array}$ & Correlation \\
\hline & $\begin{array}{c}\text { B } \\
(95 \% \mathrm{Cl})\end{array}$ & $\begin{array}{l}R^{2} \\
(R)\end{array}$ & $\begin{array}{c}\text { B } \\
(95 \% \mathrm{Cl})\end{array}$ & $\begin{array}{l}R^{2} \\
(R)\end{array}$ & $\begin{array}{c}\text { B } \\
(95 \% \mathrm{Cl})\end{array}$ & $\begin{array}{l}R^{2} \\
(R)\end{array}$ & $\begin{array}{c}\text { B } \\
(95 \% \mathrm{Cl})\end{array}$ & $\begin{array}{l}R^{2} \\
(R)\end{array}$ \\
\hline ESE & $\begin{array}{c}992 \\
(-822,2806) \\
p=0.27\end{array}$ & $\begin{array}{c}0.05 \\
(0.23) \\
p=0.27\end{array}$ & $\begin{array}{c}375 \\
(-158,908) \\
p=0.16^{*}\end{array}$ & $\begin{array}{c}0.08 \\
(0.28) \\
p=0.16^{*}\end{array}$ & $\begin{array}{c}39 \\
(2,76) \\
p=0.04 *\end{array}$ & $\begin{array}{c}0.17 \\
(0.41) \\
p=0.04^{*}\end{array}$ & $\begin{array}{c}-7 \\
(-91,78) \\
p=0.87\end{array}$ & $\begin{array}{c}0.00 \\
(0.03) \\
p=0.87\end{array}$ \\
\hline AAQ-\| & $\begin{array}{c}160 \\
(-131,452) \\
p=0.27\end{array}$ & $\begin{array}{c}0.05 \\
(0.23) \\
p=0.27\end{array}$ & $\begin{array}{c}15.7 \\
(-69,100) \\
p=0.70\end{array}$ & $\begin{array}{c}0.01 \\
(0.08) \\
p=0.70\end{array}$ & $\begin{array}{c}-0.3 \\
(-7,6) \\
p=0.92\end{array}$ & $\begin{array}{c}0.00 \\
(-0.02) \\
p=0.92\end{array}$ & $\begin{array}{c}4 \\
(-9,16) \\
p=0.57\end{array}$ & $\begin{array}{c}0.01 \\
(0.12) \\
p=0.57\end{array}$ \\
\hline PCS & $\begin{array}{c}103 \\
(-31,236) \\
p=0.13^{\star}\end{array}$ & $\begin{array}{c}0.10 \\
(0.32) \\
p=0.13^{*}\end{array}$ & $\begin{array}{c}18 \\
(-26,61) \\
p=0.41\end{array}$ & $\begin{array}{c}0.03 \\
(0.17) \\
p=0.41\end{array}$ & $\begin{array}{c}1 \\
(-2,4) \\
p=0.45\end{array}$ & $\begin{array}{c}0.02 \\
(0.16) \\
p=0.45\end{array}$ & $\begin{array}{c}1 \\
(-6,7) \\
p=0.80\end{array}$ & $\begin{array}{c}0.00 \\
(0.05) \\
p=0.81\end{array}$ \\
\hline MCS & $\begin{array}{c}69 \\
(-118,255) \\
p=0.46\end{array}$ & $\begin{array}{c}0.03 \\
(0.16) \\
p=0.46\end{array}$ & $\begin{array}{c}56 \\
(2,109) \\
p=0.04 *\end{array}$ & $\begin{array}{c}0.17 \\
(0.41) \\
p=0.04 *\end{array}$ & $\begin{array}{c}1 \\
(-3,6) \\
p=0.51\end{array}$ & $\begin{array}{c}0.02 \\
(0.14) \\
p=0.51\end{array}$ & $\begin{array}{c}9 \\
(1,17) \\
p=0.03 *\end{array}$ & $\begin{array}{c}0.20 \\
(0.45) \\
p=0.03 *\end{array}$ \\
\hline
\end{tabular}

Notes: AAQ-II-Acceptance and Action Questionnaire-II; BMI, body mass index; ESE, exercise self-efficacy; MCS, mental component score; MET, metabolic equivalents; NA, not applicable; PCS, physical component score; R, Pearson's correlation coefficient; TMOD, time spent on moderate activities; TVIG, time spent in vigorous exercise.

${ }^{*} p$ value $<0.05$ level; Bivariate regression analysis: * $p \leq 0.20$

\section{DISCUSSION}

This feasibility study is one of the first in the New Zealand health literature to provide subjective and objective PA levels and measures of psychological attributes in a small sample of individuals at risk of developing DM, recruited from the community. We have demonstrated that it is feasible to identify and recruit adults $(n=26)$ at risk of DM using a risk screening tool (administered by telephone) and to collect objective physical activity data within a relatively short period of time (5 weeks).

The results of this feasibility study demonstrate that the majority of participants (50-70\%) were classified as "low active" based on the IPAQ guidelines, whereas based on the NZPAG, a smaller proportion of participants ( 20\%) were classified as "non-active". However, based on average daily step count, the majority of participants in both groups (30-40\%) were classified as either "low active" or "somewhat active". Psychological flexibility (AAQ-II scores) was not associated with either subjective or objective measures of PA. In contrast, ESE and MCS scores were positively associated with vigorous PA minutes/week and moderate PA minutes/week, respectively.

Variations in PA levels were observed depending on the type of tool/classification scheme used for determining PA levels. The NZPAG are derived from the World Health Organisation (2010) Global Recommendations on PA for health, which includes a minimum PA target for health enhancement and prevention of non-communicable diseases. The step count incorporates all running or walking activity performed by individuals throughout the day with 10,000 steps a day associated with indicators of good health. The step count goal of 10,000 is based upon the theory that those walking 30 minutes a day achieve at least 10,000 steps. Therefore, in the context of these results, it appears our participants may have over-estimated the amount of PA they performed on a daily basis when completing the NZPAQ (Maddison et al 2007). Furthermore, many of the participants did not meet the required PA levels to reduce their risk of developing DM. However, step counting has its limitations as it only measures PA performed by walking or running and cannot account for other PA that may be measured by the NZPAQ and therefore counted towards meeting the NZPAG. Through this feasibility study, limitations of using the self-report PA tools and pedometers were identified, which in turn indicates the need for using robust PA monitoring tools (e.g. accelerometers) in future research.

In this study, average ESE scores are higher when compared to a similar New Zealand age group cohort (Mansi et al 2015). It should be noted, however, that the referenced cohort, unlike those in our study, was derived from a rural community as a part of a pedometer-driven walking programme (Mansi et al 2015). Substantial literature supports that higher self-efficacy beliefs are associated with positive health behaviours including initiation and adherence to exercise (Delahanty et al 2006, Kosma et al 2004, McAuley 1993). Interestingly, this study demonstrates that an individual with higher ESE will engage in higher duration of vigorous physical activity. However, there was no association between moderate amounts of PA and step counts. The results of the current study are in contrast with recent research on individuals with type-2 DM in which a positive association 
between moderate PA and step counts was identified (Heiss and Petosa 2016). These conflicting findings suggest that the ESE construct may not be sufficient to explain moderate PA levels in individuals at diabetic risk. Additionally, ESE may not be a mediating factor for interventions which target improving individuals' participation in moderate levels of PA. Future studies can use various components of self-efficacy dimensions (task, scheduling and coping ESE) (Rodgers et al 2008) in order to investigate the association between subjects' self-efficacy and their participation in moderate and/or vigorous PA levels.

In contrast to ESE scores, mental HRQoL is a strong determinant of moderate PA levels, but not of vigorous PA levels, suggesting that those individuals with higher mental health scores will engage in moderate PA, but not necessarily in vigorous PA (Aoyagi et al 2010, Balboa-Castillo et al 2011, Mota et al 2005). The participants' physical and mental health scores (both in total sample and the sub-sample) in this study are within the normal range of New Zealand's population means (Scott et al 1999). Previous studies have shown that HRQoL is not associated with adults who have achieved or surpassed their minimum standards of daily PA in terms of step counts (Aoyagi et al 2010, Yasunaga et al 2006). However, in this same cohort, self-perceived mental health was not associated with walking levels or participation in vigorous PA. Other studies investigating mental health and PA levels of a diabetic population (Eckert 2012) have similar findings. This study identified positive mental health as a key factor that may motivate individuals at risk of developing DM to engage in moderate levels of PA. However, in order to confirm this finding, longitudinal study designs are needed to test this hypothesis on individuals who are pre-diabetic.

A recent meta-analysis (Kan et al 2013) concluded that a small but significant cross-sectional association exists between depression and insulin resistance (pre-diabetic state). However, this study did not attempt to screen for clinical depression and other mental health issues. Considering participants' scores were within the normal scores of mental health (based on HRQoL), and a positive association between mental health scores and PA levels, one can infer that participants may not have been clinically depressed at the time of study participation. However, this claim may not be valid, since this study did not account for potential intake of anti-depressants by the study participants.

Levels of PF in this study are much lower (mean (SD): 48 (6)) than previous studies where average scores ranged from 55-59 in both physically active and inactive adults (Kangasniemi et al 2014, Mutikainen et al 2015). Such scores may be associated with the low levels of activity observed among majority of participants. Indeed, a previous study demonstrated that physically active adults demonstrated better mindfulness skills (a component of PF) in comparison to less physically active adults (Kangasniemi et al 2014). Contrary to some literature (Kangasniemi et al 2014, Kangasniemi et al 2015), we observed a non-significant association between PF and PA measures, indicating that individuals with or without greater PF engage in similar levels of PA. In support of our findings, a recent study (Mutikainen et al 2015) also reported no association between PF and PA levels, suggesting that future research should use an exercise-specific AAQ version in place of the generic AAQ-II questionnaire (Forman et al 2009).
Strengths and future research recommendations This is the first study which measured both subjective (NZPAQLF) and objective (step counts) measures of PA in a New Zealand population who were at risk of developing DM. In this study, we attempted to account for any activity performed without the pedometer being on, or activities such as cycling and swimming which are not measured by the pedometer, by having participants log such extra activities. A total of six participants across the study recorded activity they performed not measured by the pedometer. This may substantiate that few participants actually performed purposeful PA outside of walking and strengthens our results that based on pedometer activity, PA levels are low within this population. This feasibility study has identified personal factors, particularly mental health, to influence PA levels in a small sample of individuals with DM risk. Preliminary evidence for such associations of generic mental health with PA levels indicates the need for identifying the potential influence of other mental health disorders (e.g. depression) on PA levels. In addition, this study indicates the need for identifying factors associated with sedentariness, a key risk factor for all-cause mortality, cardiovascular disease, and type 2 DM (Bjork Petersen et al 2014, Wilmot et al 2012). Exploring a range of factors (personal, social and environmental, policy) of sedentary behaviour in individuals with disease risk (e.g. pre-diabetes) can be helpful to plan specific interventions targeting to modify such factors influencing their PA profiles and sedentary behaviour.

\section{Study limitations}

Limitations of this study include a small sample size, the use of pedometers to measure PA levels, the absence of a control group and not accounting for prescription medications for the treatment of depression. Considering this is a feasibility study, a multiple linear regression analysis was not attempted, thus limiting the generalisability of these findings. Since this study used an unadjusted R-square to explain the potential relationships, caution is warranted in interpreting the magnitude of variance that was explained between the variables of interest. Another key limitation of our study was that the online public health screening tool (Diabetes New Zealand, Auckland branch) used to screen participants has not yet been validated. Despite this limitation, due to its feasibility, ease of use, and specificity to New Zealand's population, it served as an appropriate tool for this study. This online tool allows health professionals to easily assess patients for diabetes risk, which facilitates early risk factor screening, and planning life-style based interventions and appropriate referral for confirmative lab-based investigations. However, further research is needed to develop a validated diabetes risk screening tool for New Zealand's multi-ethnic population.

\section{CONCLUSION}

It is feasible to screen adults $(n=26)$ at risk of DM using an online screening tool. Low levels of PA were observed among the majority of participants who have risk factors for the development of type-2 DM. Preliminary findings on associations between positive mental health and exercise self-efficacy and objective levels of PA clearly indicate the need for assessing psychological factors for effective planning of PA interventions to reduce the risk of chronic disease development. No 
association was found between psychological flexibility and measures of PA levels, suggesting that future research should use exercise-specific psychological flexibility measures. However, these observed relationships need to be confirmed in a larger sample of pre-diabetic individuals using prospective longitudinal designs for further generalisability of these findings.

\section{KEY POINTS}

1. Screening for diabetes risk using validated questionnaires is feasible in research settings.

2. Low levels of PA were observed among the majority of participants with diabetic risk.

3. Higher ESE beliefs are associated with higher amounts of vigorous $\mathrm{PA}$.

4. Better mental health (HRQoL) is associated with higher amounts of moderate PA.

\section{PERMISSIONS}

Ethical approval for this study was granted from The University of Otago Human Research Ethics Committee (Ref.no: D13/396), Dunedin, New Zealand. All participants have provided their written consent to participate in this research.

\section{DISCLOSURES}

The authors would like to acknowledge the Division of Health Sciences Summer Scholarships, University of Otago, for supporting Mr Caden Shields to complete a summer research project (November 2013 - January 2014). There are no conflicts of interest concerning this study.

\section{ADDRESS FOR CORRESPONDENCE}

Dr Ramakrishnan Mani, Centre for Health, Activity and Rehabilitation Research, School of Physiotherapy, University of Otago, PO Box 56, Dunedin, Otago, New Zealand. Telephone: +64 3479 3485. Email: ramakrishnan.mani@otago.ac.nz.

\section{REFERENCES}

American College of Sports Medicine. (2010) ACSM's Guidelines for Exercise Testing and Prescription. ( $8^{\text {th }}$ edn). Philadelphia: Wolters Kluwer Health/ Lippincott Williams \& Wilkins.

Allen NA (2004) Social cognitive theory in diabetes exercise research: An integrative literature review. Diabetes Education 30(5): 805-819. doi: 10.1177/014572170403000516.

Aoyagi Y, Park H, Park S, Shephard RJ (2010) Habitual physical activity and health-related quality of life in older adults: Interactions between the amount and intensity of activity (the Nakanojo study). Quality of Life Research 19(3): 333-338. doi:10.1007/s11136-010-9588-6.

Astroth KS, Fish AF, Mitchell GL, Bachman JA, Hsueh KH (2010) Construct validity of four exercise stage of change measures in adults. Research in Nursing and Health 33(3): 254-264. doi:10.1002/nur.20380.

Balboa-Castillo T, León-Muñoz LM, Graciani A, Rodríguez-Artalejo F, Guallar-Castillón P (2011) Longitudinal association of physical activity and sedentary behavior during leisure time with health-related quality of life in community-dwelling older adults. Health and Quality of Life Outcomes 9 doi:10.1186/1477-7525-9-47

Bandura A (1997) Self-efficacy: The Exercise of Control. New York: W.H. Freeman.

Bandura A (2004) Health promotion by social cognitive means. Health Education and Behaviour 31(2): 143-164. doi:10.1177/1090198104263660.
Battistelli A, Montani F, Bertinato L, Uras S, Guicciardi M (2012) Modelling competence motives and physical exercise intentions: The role of individual, social, and environmental characteristics. International Journal of Sport Psychology 43(6): 457-478. doi:10.7352/IJSP2012.43.457.

Bauman AE, Reis RS, Sallis JF, Wells JC, Loos RJ, Martin BW, Lancet Physical Activity Series Working G (2012) Correlates of physical activity: Why are some people physically active and others not? Lancet 380(9838): 258-271. doi:10.1016/S0140-6736(12)60735-1.

Bize R, Johnson JA, Plotnikoff RC (2007) Physical activity level and healthrelated quality of life in the general adult population: A systematic review. Preventive Medicine 45(6): 401-415. doi:10.1016/j.ypmed.2007.07.017.

Bjork Petersen C, Bauman A, Gronbaek M, Wulff Helge J, Thygesen LC, Tolstrup JS (2014) Total sitting time and risk of myocardial infarction, coronary heart disease and all-cause mortality in a prospective cohort of Danish adults. International Journal of Behavioural Nutrition and Physical Acivity 1113. doi:10.1186/1479-5868-11-13.

Bond FW, Hayes SC, Baer RA, Carpenter KM, Guenole N, Orcutt HK, Waltz T, Zettle RD (2011) Preliminary psychometric properties of the acceptance and action questionnaire-ii: A revised measure of psychological inflexibility and experiential avoidance. Behavioural Therapy 42(4): 676-688. doi:10.1016/j.beth.2011.03.007.

Boon RM, Hamlin MJ, Steel GD, Ross JJ (2010) Validation of the New Zealand physical activity questionnaire (nzpaq-If) and the international physical activity questionnaire (ipaq-If) with accelerometry. British Journal of Sports Medicine 44(10): 741-746. doi:10.1136/bjsm.2008.052167.

Brown DW, Balluz LS, Giles WH, Beckles GL, Moriarty DG, Ford ES, Mokdad $\mathrm{AH}$, behavioral risk factor surveillance system (2004) Diabetes mellitus and health-related quality of life among older adults. Findings from the behavioral risk factor surveillance system (BRFSS). Diabetes Research and Clinical Practice 65(2): 105-115. doi:10.1016/j.diabres.2003.11.014.

Bush K, Kivlahan DR, McDonell MB, Fihn SD, Bradley KA (1998) The AUDIT alcohol consumption questions (AUDIT-C): An effective brief screening test for problem drinking. Ambulatory Care Quality Improvement Project (ACQUIP). Alcohol Use Disorders Identification Test. Archives of Internal Medicine 158(16): 1789-1795.

Coppell KJ, Mann JI, Williams SM, Jo E, Drury PL, Miller JC, Parnell WR (2013) Prevalence of diagnosed and undiagnosed diabetes and prediabetes in New Zealand: Findings from the 2008/09 adult nutrition survey. New Zealand Medical Journal 126(1370): 23-42.

Crapo RO, Casaburi R, Coates AL, Enright PL, Macintyre NR, McKay RT, Johnson D, Wanger JS, Zeballos RJ, Bittner V, Mottram C (2002) ATS statement: Guidelines for the six-minute walk test. American Journal of Respiratory and Critical Care Medicine 166(1): 111-117.

Dannecker EA, Hausenblas HA, Connaughton DP, Lovins TR (2003) Validation of a stages of exercise change questionnaire. Research Quarterly for Exercise and Sport 74(3): 236-247. doi:10.1080/02701367.2003.106090 88.

Delahanty LM, Conroy MB, Nathan DM, Diabetes Prevention Program Research Group (2006) Psychological predictors of physical activity in the diabetes prevention program. Journal of the American Dietetic Association 106(5): 698-705. doi:10.1016/j.jada.2006.02.011.

Diabetes New Zealand, Auckland branch. https://diabetesauckland.org.nz/ are-you-at-risk-of-type-2-diabetes/ [Accessed January 6, 2016].

Eckert K (2012) Impact of physical activity and bodyweight on healthrelated quality of life in people with type 2 diabetes. Diabetes, Metabolic Syndrome and Obesity 5: 303-311. doi:10.2147/DMSO.S34835.

Eikenberg JD, Davy BM (2013) Prediabetes: A prevalent and treatable, but often unrecognized, clinical condition. Journal of the Academy of Nutrition and Dietetics 113(2): 213-218. doi:10.1016/j.jand.2012.10.018.

Field A (2012) Discovering Statistics using IBM SPSS Statistics (4th. edn). London: Sage Publications Ltd.

Forman EM, Butryn ML, Hoffman KL, Herbert JD (2009) An open trial of an acceptance-based behavioral intervention for weight loss. Cognitive and Behavioral Practice 16(2): 223-235. 
Haskell WL, Lee IM, Pate RR, Powell KE, Blair SN, Franklin BA, Macera CA, Heath GW, Thompson PD, Bauman A (2007) Physical activity and public health: Updated recommendation for adults from the American College of Sports Medicine and the American Heart Association. Medicine and Science in Sports and Exercise 39(8): 1423-1434. doi:10.1249/ mss.0b013e3180616b27.

Hayes SC, Luoma JB, Bond FW, Masuda A, Lillis J (2006) Acceptance and commitment therapy: Model, processes and outcomes. Behavioural Research Therapy 44(1): 1-25. doi:10.1016/j.brat.2005.06.006.

Heiss VJ, Petosa RL (2016) Social cognitive theory correlates of moderateintensity exercise among adults with type 2 diabetes. Psychology, Health and Medicine 21(1): 92-101. doi:10.1080/13548506.2015.1017510.

International Physical Activity Questionnaire. IPAQ scoring protocol, Guidelines for the data processing and analysis of the International Physical Activity Questionnaire (IPAS) - Short Form. https://sites.google. com/site/theipaq/scoring-protocol [Accessed August 15, 2016].

Izawa KP, Oka K, Watanabe S (2006) Research on exercise adherence: A review of primary studies. Critical Reviews in Physical and Rehabilitation Medicine 18(2): 92-105.

Kan C, Silva N, Golden SH, Rajala U, Timonen M, Stahl D, Ismail K (2013) A systematic review and meta-analysis of the association between depression and insulin resistance. Diabetes Care 36(2): 480-489. doi:10.2337/dc121442.

Kangasniemi A, Lappalainen R, Kankaanpää A, Tammelin T (2014) Mindfulness skills, psychological flexibility, and psychological symptoms among physically less active and active adults. Mental Health and Physical Activity 7(3): 121-127. doi:10.1016/j.mhpa.2014.06.005.

Kangasniemi AM, Lappalainen R, Kankaanpaa A, Tolvanen A, Tammelin T (2015) Towards a physically more active lifestyle based on one's own values: The results of a randomized controlled trial among physically inactive adults. BMC Public Health 15260. doi:10.1186/s12889-0151604-x.

Kashdan TB, Rottenberg J (2010) Psychological flexibility as a fundamental aspect of health. Clinical Psychology Review 30(7): 865-878. doi:10.1016/j. cpr.2010.03.001.

Klavestrand J, Vingård E (2009) The relationship between physical activity and health-related quality of life: A systematic review of current evidence. Scandinavian Journal of Medicine and Science in Sports 19(3): 300-312. doi:10.1111/j.1600-0838.2009.00939.x.

Kooiman TJ, Dontje ML, Sprenger SR, Krijnen WP, van der Schans CP, de Groot M (2015) Reliability and validity of ten consumer activity trackers. BMC Sports Science, Medicine and Rehabilitation 7: 24. doi:10.1186/ s13102-015-0018-5.

Kosma M, Cardinal BJ, McCubbin JA (2004) Predictors of physical activity stage of change among adults with physical disabilities. American Journal of Health Promotion 19(2): 114-117.

Laaksonen DE, Lindstrom J, Lakka TA, Eriksson JG, Niskanen L, Wikstrom $\mathrm{K}$, et al, Finnish diabetes prevention group (2005) Physical activity in the prevention of type 2 diabetes: The Finnish diabetes prevention study. Diabetes 54(1): 158-165.

Lillis J, Hayes SC, Bunting K, Masuda A (2009) Teaching acceptance and mindfulness to improve the lives of the obese: A preliminary test of a theoretical model. Annals of Behavioral Medicine 37(1): 58-69. doi:10.1007/s12160-009-9083-x

Maddison R, Ni Mhurchu C, Jiang Y, Vander Hoorn S, Rodgers A, Lawes CMM, Rush E (2007) International Physical Activity Questionnaire (IPAQ) and New Zealand Physical Activity Questionnaire (NZPAQ): A doubly labelled water validation. International Journal of Behavioral Nutrition and Physical Activity 4. doi:10.1186/1479-5868-4-62.

Mansi S, Milosavljevic S, Tumilty S, Hendrick P, Higgs C, Baxter DG (2015) Investigating the effect of a 3-month workplace-based pedometer-driven walking programme on health-related quality of life in meat processing workers: A feasibility study within a randomized controlled trial. BMC Public Health 15(1). doi:10.1186/s12889-015-1736-z.
Marcuello C, Calle-Pascual AL, Fuentes M, Runkle I, Soriguer F, Goday A, et al (2012) Evaluation of health-related quality of life according to carbohydrate metabolism status: A Spanish population-based study (Di@ bet.es study). International Journal of Endocrinology 2012: 872305 doi:10.1155/2012/872305.

Marcus BH, Selby VC, Niaura RS, Rossi JS (1992) Self-efficacy and the stages of exercise behavior change. Research Quarterly for Exercise and Sport 63(1): 60-66.

McAuley E (1993) Self-efficacy and the maintenance of exercise participation in older adults. Journal of Behavioral Medicine 16(1): 103-113. doi:10.1007/BF00844757.

Mota J, Ribeiro JL, Carvalho J, De Gaspar Matos M (2005) Physical activity and health - related quality of life in overweight/obese elderly women. Journal of Human Movement Studies 48(4): 245-255.

Mutikainen S, Föhr T, Karhunen L, Kolehmainen M, Kainulainen $\mathrm{H}$, Lappalainen R, Kujala UM (2015) Predictors of increase in physical activity during a 6-month follow-up period among overweight and physically inactive healthy young adults. Journal of Exercise Science and Fitness 13: 63-71. doi:10.1016/j.jesp.2015.05.001.

Orchard TJ, Temprosa M, Goldberg R, Haffner S, Ratner R, Marcovina S, Fowler S, Diabetes Prevention Program Research group (2005) The effect of metformin and intensive lifestyle intervention on the metabolic syndrome: The Diabetes Prevention Program randomized trial. Annals of Internal Medicine 142(8): 611-619.

Orozco LJ, Buchleitner AM, Gimenez-Perez G, Figuls MR, Richter B, Mauricio D (2008) Exercise or exercise and diet for preventing type 2 diabetes mellitus. Cochrane Database of Systematic Reviews (3). doi:10.1002/14651858.CD003054.pub3.

Papandonatos GD, Williams DM, Jennings EG, Napolitano MA, Bock BC Dunsiger S, Marcus BH (2012) Mediators of physical activity behavior change: Findings from a 12-month randomized controlled trial. Health Psychology 31(4): 512-520. doi:10.1037/a0026667.

Rhodes RE, Pfaeffli LA (2010) Mediators of physical activity behaviour change among adult non-clinical populations: A review update. International Journal of Behavioral Nutrition and Physical Activity 7. doi:10.1186/1479 5868-7-37

Rodgers WM, Wilson PM, Hall CR, Fraser SN, Murray TC (2008) Evidence for a multidimensional self-efficacy for exercise scale. Research Quarterly for Exercise and Sport 79(2): 222-234. doi:10.1080/02701367.2008.105994 85

Sacco WP, Wells KJ, Friedman A, Matthew R, Perez S, Vaughan CA (2007) Adherence, body mass index, and depression in adults with type 2 diabetes: The mediational role of diabetes symptoms and self-efficacy. Health Psychology 26(6): 693-700. doi:10.1037/0278-6133.26.6.693.

Sacco WP, Wells KJ, Vaughan CA, Friedman A, Perez S, Matthew R (2005) Depression in adults with type 2 diabetes: The role of adherence, body mass index, and self-efficacy. Health Psychology 24(6): 630-634. doi:10.1037/0278-6133.24.6.630

Scott KM, Tobias MI, Sarfati D, Haslett SJ (1999) SF-36 health survey reliability, validity and norms for New Zealand. Australian and New Zealand Journal of Public Health 23(4): 401-406. doi: 0.1111/j.1467-842X.1999. tb01282x

Seppälä T, Saxen U, Kautiainen H, Järvenpää S, Korhonen PE (2013) Impaired glucose metabolism and health related quality of life. Primary Care Diabetes 7(3): 223-227. doi:10.1016/j.pcd.2013.03.001.

Tabak AG, Herder C, Rathmann W, Brunner EJ, Kivimaki M (2012) Prediabetes: A high-risk state for diabetes development. Lancet 379(9833): 2279-2290. doi:10.1016/S0140-6736(12)60283-9.

Tapp RJ, Dunstan DW, Phillips P, Tonkin A, Zimmet PZ, Shaw JE, AusDiab Study Group (2006) Association between impaired glucose metabolism and quality of life: Results from the Australian diabetes obesity and lifestyle study. Diabetes Research and Clinical Practice 74(2): 154-161. doi:10.1016/j.diabres.2006.03.012. 
Taylor LM, Spence JC, Raine K, Plotnikoff RC, Vallance JK, Sharma AM

(2010) Physical activity and health-related quality of life in individuals with prediabetes. Diabetes Research and Clinical Practice 90(1): 15-21. doi:10.1016/j.diabres.2010.04.011.

Tudor-Locke C, Bassett DR, Jr. (2004) How many steps/day are enough? Preliminary pedometer indices for public health. Sports Medicine 34(1): 1-8.

Wilmot EG, Edwardson CL, Achana FA, Davies MJ, Gorely T, Gray L, Khunt $K$, Yates T, Biddle SJ (2012) Sedentary time in adults and the association with diabetes, cardiovascular disease and death: Systematic review and meta-analysis. Diabetologia 55(11): 2895-2905. doi:10.1007/s00125-0122677-z

World Health Organisation. (2010). Global recommendations on physical activity for health. ISBN 9789241599979 [Accessed January 6, 2016]

Yasunaga A, Togo F, Watanabe E, Park H, Shephard RJ, Aoyagi Y (2006) Yearlong physical activity and health-related quality of life in older Japanese adults: The Nakanojo study. Journal of Aging and Physical Activity 14(3): 288-301.

Zhang L, Zhang Z, Zhang Y, Hu G, Chen L (2014) Evaluation of Finnish Diabetes Risk Score in screening undiagnosed diabetes and prediabetes among U.S. adults by gender and race: NHANES 1999-2010. PLOS ONE 9(5): e97865. doi:10.1371/journal.pone.0097865 